University of Nebraska - Lincoln

DigitalCommons@University of Nebraska - Lincoln

USDA National Wildlife Research Center - Staff Publications
U.S. Department of Agriculture: Animal and Plant Health Inspection Service

2011

\title{
A Retrospective Economic Analysis of the Ontario Red Fox Oral Rabies Vaccination Programme
}

\author{
S. A. Shwiff \\ USDA/APHIS/WS National Wildlife Research Center, stephanie.a.shwiff@aphis.usda.gov \\ C. P. Nunan \\ Trent University \\ Katy N. Kirkpatrick \\ USDA/APHIS/WS National Wildlife Research Center, Katy.N.Kirkpatrick@aphis.usda.gov
}

S. S. Shwiff

Texas A \& M University, Steven.Shwiff@tamuc.edu

Follow this and additional works at: https://digitalcommons.unl.edu/icwdm_usdanwrc

Shwiff, S. A.; Nunan, C. P.; Kirkpatrick, Katy N.; and Shwiff, S. S., "A Retrospective Economic Analysis of the Ontario Red Fox Oral Rabies Vaccination Programme" (2011). USDA National Wildlife Research Center Staff Publications. 1368.

https://digitalcommons.unl.edu/icwdm_usdanwrc/1368

This Article is brought to you for free and open access by the U.S. Department of Agriculture: Animal and Plant Health Inspection Service at DigitalCommons@University of Nebraska - Lincoln. It has been accepted for inclusion in USDA National Wildlife Research Center - Staff Publications by an authorized administrator of DigitalCommons@University of Nebraska - Lincoln. 


\title{
A Retrospective Economic Analysis of the Ontario Red Fox Oral Rabies Vaccination Programme
}

\author{
S. A. Shwiff ${ }^{1}$, C. P. Nunan ${ }^{2}$, K. N. Kirkpatrick ${ }^{1}$ and S. S. Shwiff ${ }^{3}$ \\ 1 USDA, APHIS, Wildlife Services, National Wildlife Research Center, Ft. Collins, CO, USA \\ 2 Wildlife Research and Development Section, Ontario Ministry of Natural Resources, DNA Building, Trent University, Ontario, Canada \\ ${ }^{3}$ Department of Accounting, Economics and Finance, Texas A \& M University - Commerce, Commerce, TX, USA
}

\section{Impacts}

- Economic analysis provides an additional tool to assist legislators and public officials in the decision making process with regard to rabies control programmes.

- This manuscript provides a framework for economic assessment of rabies control programmes and outlines multiple techniques for estimating benefits when uncertainty exists.

- Study findings provide support for large scale rabies control programmes and the analysis provides an explanation of intangible benefits that should additionally be considered.

\section{Keywords:}

Canada; rabies; economics; cost-benefit analysis; rabies vaccine; foxes Vulpes

\section{Correspondence:}

S. Shwiff. The National Wildlife Research Center, 4101 LaPorte Avenue, Fort Collins, CO 80521, USA. Tel.: 9702666150; Fax: 9702666157; E-mail: stephanie.a.shwiff@ aphis.usda.gov

Received for publication May 19, 2009

doi: $10.1111 / j .1863-2378.2010 .01335 . x$

\section{Summary}

Ontario initiated a red fox (Vulpes vulpes) oral rabies vaccination (ORV) programme in 1989. This study utilized a benefit-cost analysis to determine if this ORV programme was economically worthwhile. Between 1979 and 1989, prior to ORV baiting, the average annual human post-exposure treatments, positive red fox rabies diagnostic tests and indemnity payments for livestock lost to rabies were 2248, 1861 and $\$ 246809$, respectively. After baiting, from 1990 to 2000 , a $35 \%, 66 \%$ and $41 \%$ decrease in post-exposure treatments, animal rabies tests and indemnity payments was observed, respectively. These reductions were viewed as benefits of the ORV programme, whereas total costs were those associated with ORV baiting. Multiple techniques were used to estimate four different benefit streams and the total estimated benefits ranged from $\$ 35486316$ to $\$ 98413217$. The annual mean ORV programme cost was $\$ 6447720$, with total programme costs of $\$ 77372637$. The average benefit-cost ratios over the analysis period were $.49,1.06,1.27$ and 1.36 , indicating overall programme efficiency in three of the four conservative scenarios.

\section{Introduction}

In 1979, the Ontario Ministry of Natural Resources (OMNR) embarked on an ambitious plan to control rabies in the province of Ontario. In previous years, Ontario had the dubious distinction of being the rabies capital of North America because of the consistently large numbers of human post-exposure treatment (PET) and domestic and companion animal rabies cases. Reasoning that the large numbers of cases came from Ontario wildlife, scientists working on rabies with the OMNR felt that wildlife vaccination was the most direct and cost-efficient way of reducing the effects of rabies in the Province (MacInnes et al., 2001; Nunan et al., 2002).

Work began on the development of an attractant and vaccine package that would withstand aerial delivery, and an aerial delivery system (Bachmann et al., 1990; MacInnes et al., 2001). In 1989, all aspects of the programme were ready and preliminary baiting in eastern Ontario was begun. Bolstered by initial successes, the programme was quickly increased to encompass the entire rabies endemic area of the province, which included all of southern Ontario as well as large urban areas such as greater metro Toronto (Rosatte et al., 
2007). At its height, the programme delivered more than 2 million baits and had an annual budget of almost $\$ 7$ million (Table 1).

A comprehensive analysis of PETs, animal rabies tests and indemnity payments for rabies-caused deaths of livestock in Ontario Province between 1989 and 2000 was performed to better quantify the OMNR ORV programme (Nunan et al., 2002). Numerous economic data have been used to characterize rabies-related impacts (Meltzer and Rupprecht, 1998a,b). Several ex post studies have quantified both rabies- and ORV-incurred costs (Uhaa et al., 1992; Kreindel et al., 1998; Chang et al., 2002; Foroutan et al., 2002; Nunan et al., 2002; Shwiff et al., 2007, 2008; ) and additionally, two studies have modelled ORV economics using benefit-cost analysis (BCA) (Meltzer, 1996; Kemere et al., 2002). Costs of PETs have been used routinely as the single greatest rabiesinduced expense to society (Meltzer and Rupprecht, 1998a; b). More recently, an ex post analysis of 5 years of rabies-related records for clinics and public health agencies in San Luis Obispo and Santa Barbara counties California estimated both direct and indirect costs of rabies (Shwiff et al., 2007).

We describe a comprehensive BCA of the OMNR ORV programme for Arctic variant rabies in the Ontario province from 1989 to 2000. Initially, an analysis of variance (ANOVA) examines the variables pre- and post-ORV to determine if there is a significant difference between the average level of PETs, animal rabies tests and indemnity payments before and after the initiation of the ORV programme (pre- versus post-ORV). It further provides an economic assessment of empirical costs and potential savings to the province associated with the ORV programme, as well as a sensitivity analysis to broaden the scope of the results of this analysis.

Table 1. Total annual budget for the Ontario oral rabies vaccination programme in 2006 CAD (1989-2000)

\begin{tabular}{ll}
\hline Year & ORV programme costs \\
\hline 1989 & $\$ 4955110$ \\
1990 & $\$ 13403946$ \\
1991 & $\$ 8918718$ \\
1992 & $\$ 4808712$ \\
1993 & $\$ 3732025$ \\
1994 & $\$ 4943335$ \\
1995 & $\$ 6165058$ \\
1996 & $\$ 6162402$ \\
1997 & $\$ 6190792$ \\
1998 & $\$ 5198597$ \\
1999 & $\$ 5597983$ \\
2000 & $\$ 7295960$ \\
Total & $\$ 77372637$ \\
\hline
\end{tabular}

\section{Materials and Methods}

We gathered data on PET, animal rabies tests (AT) and indemnification (INDEM) from several sources (Figs 1-3) (Nunan et al., 2002). Data were available on the number of human PETs from 1959 to 2000, animals that tested positive from 1960 to 2000 and indemnity payments from 1979 to 2000. All of the data available for each variable were used when calculating the trend in the variables; however, when calculating the average cases during the pre- and post-ORV time periods, only data were used from 1979 to 1989 and 1990 to 2000, respectively. Information on costs of human PETs was unavailable, and therefore was estimated. The annual cost of the Rabies Indemnification Programme over the study period was obtained from the Ontario Ministry of Agriculture, Food and Rural Affairs. The Rabies Indemnification Programme provides reimbursements to ranchers whose livestock were lost to the disease. Information on the cost of all OMNR Rabies Research Unit activities, including all information regarding bait and delivery system development, including actual bait dropping, were obtained directly from the OMNR, Rabies Research Unit (Nunan et al., 2002).

The PET and AT time series were tested for a unit root and both were determined to be stationary. Both series have autocorrelation functions (ACF) that decay rapidly with $t$-values falling below the practical warning level of 1.6 after lag 2 for PET, and lag 3 for AT and INDEM. Therefore, forecasting methods were chosen that would be applicable to stationary time series. The data exhibit no seasonality with ACF $t$-values less than 1.3 , the practical warning level for seasonal lengths. PET and AT both offered sufficient pre-intervention data justifying the application of standard stationary, non-seasonal time series techniques.

A cursory inspection of the data suggests that on average the pre-intervention period has a higher mean than the post-period. A quick way to determine this is to use an ANOva to test the pre- versus post-levels of PET, AT and INDEM. A means equality test was performed based on a single-factor, between-subjects ANOva. If the subgroups have the same mean, then the variability between the sample means (between groups) should be the same as the variability within any subgroup (within group). This type of analysis determines if the means of two groups differ. Expectations regarding the pre- versus post-ORV means of PET, AT and INDEM were that as a result of the OMNR ORV programme, the means in the post-ORV years were significantly lower than in the pre-ORV years. All data were analysed using the EVIEws6 software program (Quantitative Micro Software, 1994). 


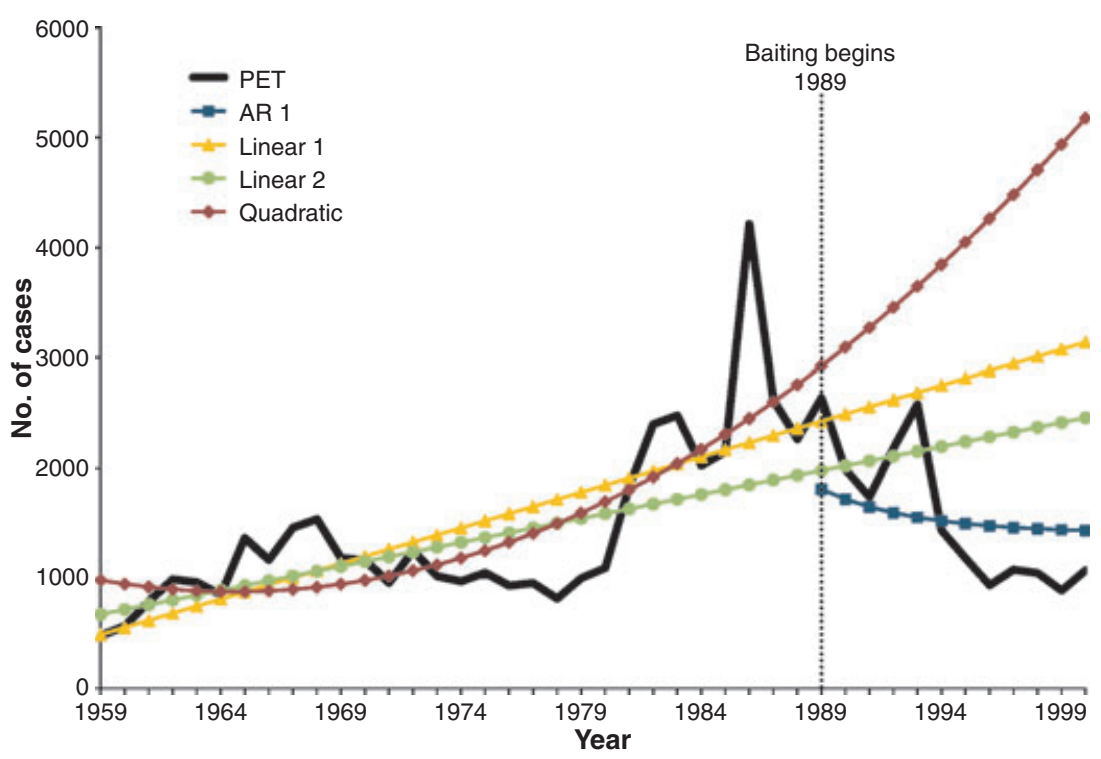

Fig. 1. Number of post-exposure treatments administered in Canada versus the number predicted in the absence of oral rabies vaccine baiting (1959-2000).

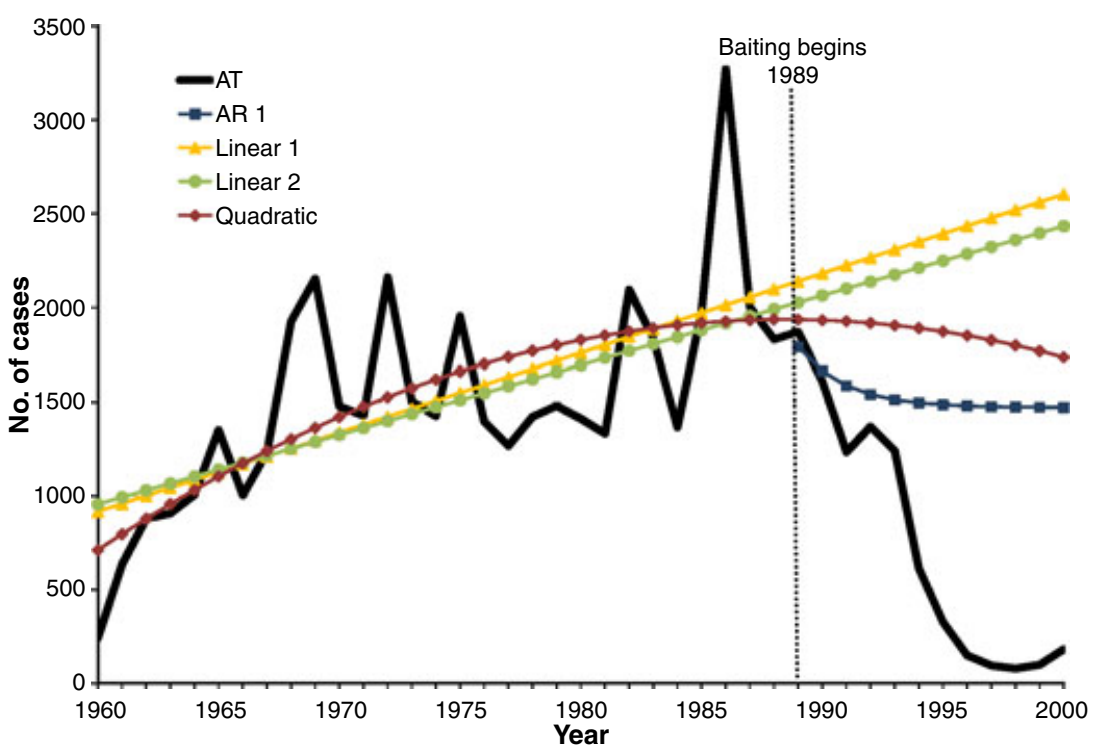

Fig. 2. Number of animals testing positive for rabies in Canada versus the number predicted in the absence of oral rabies vaccine baiting (19602000).

Benefit-cost analysis is a common tool used by economists to evaluate government programmes and determine the efficiency of management efforts. In this BCA, the monetary benefits and costs of the OMNR ORV programme actions were identified and compared. Benefitcost analysis is most often used when there are non-marketed goods and services to value, such as environmental goods. The service of protecting human health and safety from red fox rabies involves non-market items. To measure such values, a number of concepts and measurement techniques have been developed (Zerbe and Dively, 1994).

One accepted methodology to value non-market services is the damage-avoided method (King and Mazzotta, 2006). The damage-avoided method uses the value of human health and safety resources protected, in this case PETs, AT and INDEM, as a measure of the benefits 
provided by the OMNR ORV programme (Boardman et al., 1996). Here, it was posited that the ORV programme contained and prevented the spread of this variant through the rest of the province and potentially to other parts of Canada. Conversely, if the OMNR were to cease the ORV programme, cases of the disease would likely increase and spread throughout the Province.

Benefit-cost analyses are typically performed prior to the actual start of the programme under study. As this was a retrospective study, the actual programme commencement preceded the BCA. Commonly, economic valuation of cost is more easily accomplished than valuation of benefit. This was true in the case of the OMNR ORV Programme in Ontario, as the benefits are enjoyed by many (the entire population of the province) and the costs are borne by only a few (the government). Because costs of all aspects of the ORV Programme were borne by the government, we determined that all benefits of the ORV Programme should accrue to the provincial budget as well, reducing the amount of data and the number of information sources that were necessary.

Benefits were largely driven by the expected savings from reduced costs associated with the burden of the disease. Benefits were the savings associated with the reduced number of human exposures, reduced number of animal tests and fewer indemnity payments. Costs were incurred for baits, air time, fuel, ground baiting, surveillance, project planning and evaluation.

Baiting began in 1989 and this year was included in the pre-ORV calculation of the average number of cases of PET, AT and INDEM because this initial year of baiting was unique. The vaccine did not actively protect the fox population in eastern Ontario until late in the year. Therefore, the pre-ORV time period includes 1979-1989 and the post-ORV period was from 1990 to 2000 when calculating the average number of cases for each variable. We constructed our BCA in terms of four different forecasting techniques to provide a range of estimates of future cases of PET, AT and indemnity payments, to attempt to reduce uncertainty about the magnitude of the impact we predict and the values we assign to them.

For this study, total benefits (TB) of the ORV programme were equal to the savings resulting from the ORV programme operation since 1989. Data indicate that as a result of initiation, PETs, AT and INDEM decreased. These decreases were seen as the benefits of the OMNR ORV programme.

The annual TB equal the PET costs, AT costs and INDEM saved,

$$
\mathrm{TB}^{y}=\mathrm{PET}_{\text {saved }}^{y}+\mathrm{AT}_{\text {saved }}^{y}+\operatorname{INDEM}_{\text {saved }}^{y},
$$

where $y$ represents the year.
Three steps were necessary to determine the savings that resulted from the operation of the OMNR ORV programme. First, it was necessary to predict the number of cases that would have existed in the absence of the ORV programme, based on the data prior to the initiation. Second, the annual cost of each variable was determined by multiplying the number of predicted cases by the variable cost. Third, to determine overall savings, the observed level of each of the three variables in Equation 1 was subtracted from the estimated level. The determination of savings for each variable will be discussed in detail below.

To determine $\mathrm{PET}_{\text {saved, }}$, the first step was to predict the number of cases that would have existed in the absence of the OMNR ORV programme (Fig. 1). To do this, we used four different forecasting techniques including a simple Box-Jenkins autoregressive (AR 1) model, a quadratic (QUAD) and two different linear regression (LINEAR 1 and LINEAR 2) estimates. For the LINEAR 1 estimate, we fit a linear regression to the pre-ORV period $(\leq 1989)$ and then forecasted that trend into the postORV period (1990-2000). For the LINEAR 2 estimate, we again fit a linear regression however this estimate omitted the peak in the data at 1986, which makes the slope of LINEAR $1>$ LINEAR 2. The linear fit in the pre-ORV period suggests that on average the annual number of fox rabies related PET cases were increasing each year. We assumed that this fit in the post-ORV period indicates the number of cases that would have occurred if the ORV programme had never existed.

The difference between the predicted $\left(\mathrm{PET}^{y}\right)$ and actual $\left(\mathrm{PET}_{\text {actual }}^{y}\right)$ PETs represents the savings resulting from the ORV programme. Therefore,

$$
\mathrm{PET}_{\text {saved }}^{y}=\left(\mathrm{PET}^{y}-\mathrm{PET}_{\text {actual }}^{y}\right) \mathrm{PET}_{\text {costs }} .
$$

We estimated $\mathrm{PET}_{\text {cost }}$ from correspondence with personnel involved in providing the vaccine. Values for a single PET varied between $\$ 2500$ in Pennsylvania (MacInnes et al., 2001) and \$1500-2500 USD (\$1770-\$2950 CAD) for the entire United States (C. Rupprecht, personal communication). Shwiff et al. (2007) determined that PET (PEP) costs were $\$ 2540$ USD or approximately $\$ 3000$ CAD in 2006 dollars. In Canada, as of January 2004, the cost of the biologics used in rabies PET was approximately $\$ 1021$ (\$1108 2006 CAD) (D. Middleton, personal communication). We felt that a value between the United States and the Canadian estimates more closely represented the actual amount paid for PET in Ontario, and we used an estimate of $\$ 1750$ in 2006 CAD.

In addition to direct cost of a rabid animal exposure, indirect costs should be considered. Although the direct costs include the vaccine and other biologics, indirect costs refer to things like over-the-counter medicines, 


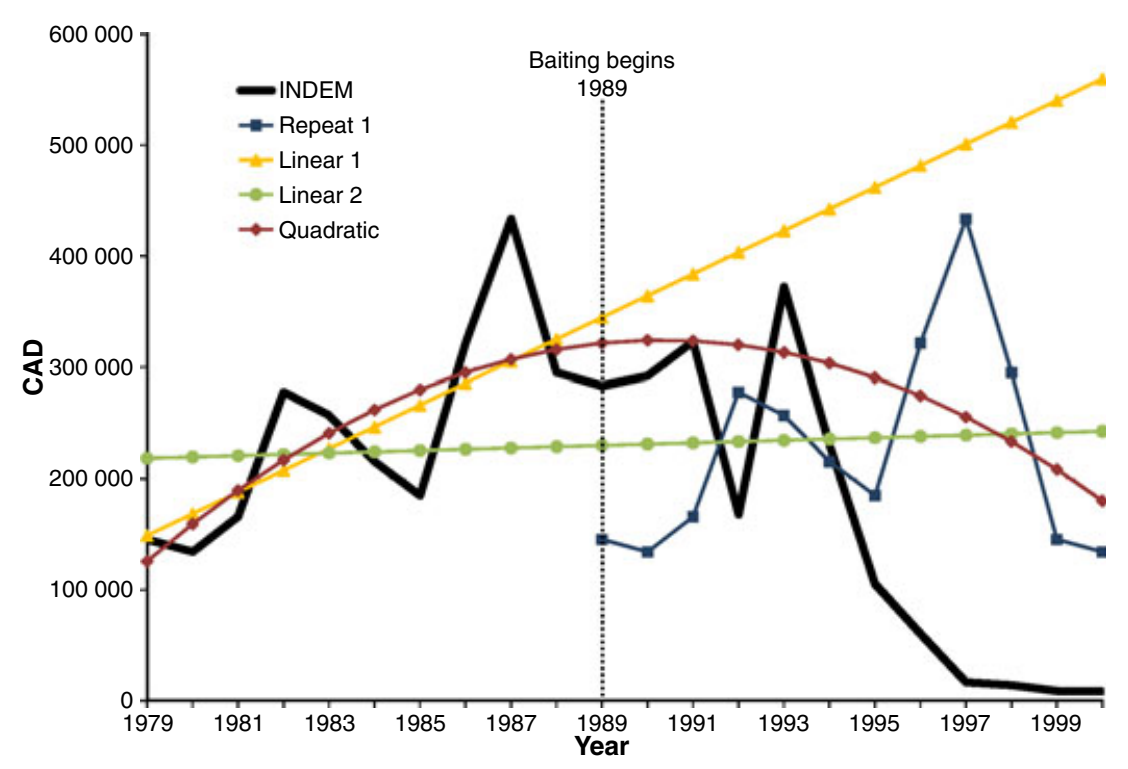

Fig. 3. Amount paid out from the rabies indemnification programme in Canada versus the amount predicted in the absence of oral rabies vaccine baiting (1978-2000).

travel to physicians and lost time from work associated with treatment. Indirect costs have been estimated to compose approximately one-third of the TC associated with a rabid animal exposure (Shwiff et al., 2007). However, only direct costs were included.

The calculation of savings related to AT were similar to PET. The number of positive animals represents only a fraction of the costs that were incurred to test animals suspected of having rabies. The number of animals that tested negative for rabies was not available for this study, so the approximate total number of animals tested had to be derived. A study by Shwiff et al. (2007) found that over a 10-year period (1991-2000) in California approximately 1 in every 5.27 skunks tested were rabies positive. Extrapolating this proportion to Canada was most likely conservative because in some years during the 1980 s at the height of the rabies enzootic, 15000 to 25000 rabies investigations involving public health officials were carried out annually (Nunan et al., 2002). The cost information for testing animals for rabies was based upon indications from the Ontario Ministry of Health that placed the costs at $\$ 650$ per test. This value was consistent with the findings of the Shwiff et al.'s (2007) study.

Calculation of the $\mathrm{AT}_{\text {savings }}$ portion of Equation 1 involves an equation similar to Equation 2, with the exception that animals testing negative must be included. This calculation was accomplished through a scalar (5.27 as mentioned above), producing an estimate of the total number of animals tested (Fig. 2). Therefore,

$$
\mathrm{AT}_{\text {saved }}^{y}=\left[\left(\hat{\mathrm{AT}}^{y}-\mathrm{AT}_{\text {actual }}^{y}\right) \times 5.27\right] \mathrm{AT}_{\text {costs }}
$$

represents the savings associated with the reduction in the total number of animals tested for rabies.

Indemnity payments were the last portion of the benefits equation included. These payments began in 1979, reached a peak in 1987 and then slowly declined after 1995, likely because of the initiation of the OMNR ORV programme in 1989. As with the PET and AT, it was necessary to predict the number of cases (or payment volume) that would have existed in the absence of the ORV programme (Fig. 3). The pre-intervention data for INDEM were limited, making the use of standard time series techniques problematic. This caused a modification of the some of the four forecasting techniques used including, a naive forecasting method which simply repeated the data set over the forecast range (REPEAT 1) instead of an AR 1 model and the linear regression of REPEAT 1 as the estimate for LINEAR 2. The QUAD and LINEAR 1 estimates were conducted using the same methodology as in PET and AT.

The methods described above were employed to make the projections, with the exception of the cost variable. The equation used to calculate indemnity was:

$$
\operatorname{INDEM}_{\text {saved }}^{y}=\left(\mathrm{INDEM}^{y}-\operatorname{INDEM}_{\text {actual }}^{y}\right) .
$$

Estimation of all three of the components of Equation 1 permits the determination of $\mathrm{TB}$. 
The estimation of TB over the entire period since the initiation of the ORV programme can be written by substituting Equations 2-4 in Equation 1: in current dollars, there was a statistical difference at the $10 \%$ level in the pre- $(\$ 246809 \pm \$ 26887)$ and post-ORV (\$145 $327 \pm \$ 41836)$ periods $(P=0.0547)$.

$$
\mathrm{TB}=\sum_{y=1989}^{2000}\left\{\left(\hat{\mathrm{PET}}^{y}-\mathrm{PET}_{\mathrm{actual}}^{y}\right) \mathrm{PET}_{\text {costs }}+\left[\left(\hat{\mathrm{AT}}^{y}-\mathrm{AT}_{\mathrm{actual}}^{y}\right) \times 5.27\right] \mathrm{AT}_{\text {costs }}+\left(\mathrm{INDEM}^{y}-\mathrm{INDEM}_{\mathrm{actual}}^{y}\right)\right\}
$$

All estimates of costs and indemnity payments are given in 2006 dollars.

The cost composition was determined from the total expenditures on the OMNR ORV programme from 1989 to 2000. Total costs were divided into three major categories: rabies unit costs, contract costs and bait machinery costs. The largest portion of costs during the ORV programme was under the category of contract costs for bait manufacture, which made up roughly $38 \%$ of the TC. Total costs for the time period relevant for this study (1989-2000) were \$77 372637 in 2006 CAD (Table 1). This was the value included in the analysis to determine the overall efficiency of the OMNR ORV programme.

The benefit-cost ratios (BCRs) were calculated using the standard format of the ratio of benefits to costs (Loomis, 1993; Zerbe and Dively, 1994; Boardman et al., 1996; Nas, 1996; Loomis and Walsh, 1997). The basic BCR was calculated from the equation:

$$
\begin{aligned}
\mathrm{BCR} & =\frac{\text { Benefits }}{\text { Costs }} \\
& =\frac{\$ \text { value of PET, AT and indemnity costs saved }}{\$ \text { cost of ORV baiting }}(6)
\end{aligned}
$$

A BCR of 1.0 would indicate that the benefits and costs were equal, or in other words, 1 unit of costs yields 1 unit of benefits. A BCR greater than 1.0 would indicate that the benefits of the ORV programme outweigh the costs, and that the monies allocated to the project were economically efficient. Often, it is the case for multi-year projects that the best determination of efficiency is over the entire lifetime of the project rather than over a single year.

\section{Results}

The results for the ANOVA confirm expectations regarding the initiation of the ORV programme in 1989. The results (mean $\pm \mathrm{SE}$ ) indicate that for human PET there was a statistical difference at the $5 \%$ level in the pre$(2248 \pm 258)$ and post-ORV $(1468 \pm 173)$ periods $(P=0.0207)$ (Fig. S1). The results for AT indicate that at the $1 \%$ level, there was a difference in the pre$(1861 \pm 164)$ and post-ORV $(637 \pm 182)$ periods $(P=0.0001)$ (Fig. S1). Finally, for indemnity payments,
These results confirm that in comparison to the preORV period, the post-ORV period saw lower rates of human PET, AT and indemnity payments on average (Fig. S2). The results of the BCA will determine if this reduction produces enough savings to justify the costs and establish economic efficiency for the whole ORV programme.

Benefits were estimated using four different forecasting techniques, including a simple Box-Jenkins autoregressive (a repeat model for INDEM), a quadratic and two different linear regressions, and are presented in Table 2. These estimated benefits were calculated over the study period and range from \$35 486316 to \$98 413 217. The per cent of the total that PET, AT and INDEM savings represent vary depending upon the forecasting method used. For all methods, INDEM made up a minor amount of the total savings $(\leq 5 \%)$. For the AR $1 /$ Repeat method, PET made up the majority of the TB whereas for all of the other methods benefits associated with reduced AT costs were the largest component of the total.

We calculated the BCRs by summing the savings to PET, AT and INDEM resulting from the initiation of the OMNR ORV programme and comparing them to the annual costs (Table 3). Overall programme economic efficiency $(\mathrm{BCR}>1.0)$ was achieved in three of the four forecasting estimates. The only forecasting methodology that did not yield economic efficiency was the AR1 estimate which was also the most conservative. This was not surprising because this estimation methodology weights the most recent observations higher than past observations meaning that the upward trend in the data until 1986 was weighted less than the downward trend from 1987 to 1989 , which gave an overall downward trend to the predicted future values from 1990 to 2000 (Enders, 1995).

In the early years of baiting, under the Linear 1, 2 and Quadratic estimates the BCRs in 1990-1992 (1993 for Linear 2) were less than 1.0 (although increasing), meaning that the benefits experienced through savings, were not large enough to justify baiting in those years. Because of the lag time of the PET savings, the true savings were not seen until later years, as represented by BCRs greater than 1.0 from 1993 to 2000. For example, the BCRs under these three scenarios peaked in 1998 at greater than 2, when the benefits to society were over twice the cost of the OMNR ORV programme. The overall BCRs, since the 
Table 2. Benefits of the Ontario oral rabies vaccination programme in 2006 CAD (1990-2000)

\begin{tabular}{|c|c|c|c|c|c|c|c|}
\hline \multirow[b]{2}{*}{ Forecasting Method } & \multicolumn{2}{|l|}{ PET } & \multicolumn{2}{|l|}{ AT } & \multicolumn{2}{|l|}{ INDEM } & \multirow[b]{2}{*}{ Total programme benefits } \\
\hline & Benefits & $\%$ of total & Benefits & $\%$ of total & Benefits & $\%$ of total & \\
\hline AR 1/Repeat & $\$ 33076217$ & 93 & $\$ 1173970$ & 3 & $\$ 1236129$ & 3 & $\$ 35486316$ \\
\hline Linear 1 & $\$ 25602,933$ & 26 & $\$ 67065367$ & 68 & $\$ 5240224$ & 5 & $\$ 97908524$ \\
\hline Linear 2 & $\$ 14920880$ & 19 & $\$ 60729267$ & 79 & $\$ 1329842$ & 2 & $\$ 76979988$ \\
\hline Quadratic & $\$ 45943491$ & 47 & $\$ 50365786$ & 51 & $\$ 2103940$ & 2 & $\$ 98413217$ \\
\hline
\end{tabular}

Table 3. Benefit-cost ratios for Ontario oral rabies vaccination programme (1990-2000)

\begin{tabular}{|c|c|c|c|c|}
\hline \multirow[b]{2}{*}{ Year } & \multicolumn{4}{|l|}{ BCRs } \\
\hline & AR 1/Repeat & Linear 1 & Linear 2 & Quadratic \\
\hline 1990 & -0.04 & 0.22 & 0.11 & 0.23 \\
\hline 1991 & 0.09 & 0.55 & 0.38 & 0.57 \\
\hline 1992 & -0.05 & 0.88 & 0.54 & 0.91 \\
\hline 1993 & -0.28 & 1.05 & 0.59 & 1.08 \\
\hline 1994 & 0.64 & 1.74 & 1.38 & 1.76 \\
\hline 1995 & 0.75 & 1.70 & 1.40 & 1.72 \\
\hline 1996 & 0.96 & 1.93 & 1.61 & 1.94 \\
\hline 1997 & 0.97 & 1.96 & 1.64 & 1.97 \\
\hline 1998 & 1.13 & 2.40 & 2.01 & 2.42 \\
\hline 1999 & 1.05 & 2.32 & 1.94 & 2.33 \\
\hline 2000 & 0.71 & 1.73 & 1.43 & 1.74 \\
\hline Average & 0.49 & 1.27 & 1.06 & 1.36 \\
\hline
\end{tabular}

ORV Programme's inception, under the Linear 1, 2 and Quadratic scenarios were 1.06, 1.27 and 1.36, respectively. This can be interpreted as, for every dollar spent, between $\$ 1.06$ and \$1.36 in savings was realized. The results of the BCA indicate that programme efficiency was gained under the assumptions made in the analysis. Many of the assumptions in this analysis lend to these results being conservative.

The results from the AR1 estimates indicate that in all years except 1998 and 1999, programme efficiency was not achieved. The AR1 process was not used to forecast INDEM because of data limitations so the data were simply repeated in the future. Given the nature of the AR1 forecast, the lowest savings were garnered under this scenario for both PET and AT, especially in the initial years of baiting. The downward estimation of the AR1 estimate suppressed potential savings resulting from the ORV programme decreasing the number of PET and AT administered, which created a situation in which the costs exceeded the benefits for this scenario.

\section{Discussion}

The choice of forecasting technique clearly played a role in the determination of overall programme efficiency.
Three of the four forecasting techniques indicated an upward trend to the data. The AR1 process, however, indicated an overall decrease in the number of future cases given the most recent trends in the data, which, contrary to the other techniques, does not equally weight all of the observations, instead more weight is given to the most recent observations. The two linear regressions and the quadratic estimates indicated that the OMNR ORV programme was successful, based on the reductions in PETs, AT and INDEM (Hauschildt et al., 2001; MacInnes et al., 2001; Nunan et al., 2002). Additionally, based on assumptions, results show that the OMNR ORV programme was cost efficient under these three estimates, which yielded an overall programme BCR greater than 1 . As expected, the first 2 years of the study were not cost effective, because bait distribution techniques were still being developed and only a portion of the rabies endemic areas were baited. Obviously, removing the two initial years from the analysis would increase the overall BCRs and would result in greater programme efficiency. The results of these three scenarios confirm the cost effectiveness of a limited regional use of an ORV strategy involving canids. Although MacInnes et al. (2001) reported success of this strategy to eliminate arctic-fox-(Alopex lagopus)-variant rabies from red fox vectors in southern Ontario Province, Canada, they provided no economic data for their programme. But, economics can often be the basis for the justification and the rationale of such programmes.

Each forecasting method is not intended to suggest that these trends will continue ad infinitum, but rather over the short-term to 2000. Additionally, no suggestion is made regarding which technique provides the 'best' fit for forecasting the data. All forecasting techniques have limitations. Therefore, multiple estimations of future potential trends in the data were projected to provide an array of possible future scenarios to minimize the uncertainty surrounding the projection of overall results.

It has been argued that disease epizootics are cyclical in that a population of sick animals increases for a period of time and then dissipates as die off occurs (MacInnes et al., 2001). Upon examining this data set, cyclical trends 
appear in the PET and INDEM data but were not present in the data for AT. For PET, the cycle was approximately every 19-20 years, whereas for INDEM every 5-6 years. Interestingly, in both cases (PET and INDEM), the overall average of the number of animals involved in a 'cycle' was increasing suggesting that overtime each 'cycle' involves more animals, which was consistent with the three upward trending forecasts and inconsistent with the AR1 forecast.

The inclusion of more comprehensive rabies-caused cost impacts (i.e. pet vaccinations, livestock vaccinations, rabies educational programmes, human deaths, pet replacements, etc.) as sources of potential benefits would undoubtedly have increased the projected OMNR ORV programme benefits substantially. For example, Uhaa et al. (1992) reported 20\% increased pet vaccinations occurred in the New Jersey epizootic of raccoon rabies as 'once-negligent' pet owners rushed to protect their pets from the disease outbreak. Intangible benefits also exist as a result of the OMNR ORV programme, but were difficult to quantify monetarily. These benefits include increased quality of life for the residents of the baited areas. There is a certain level of perceived risk of infection experienced by individuals living in a rabies epizootic region. Actual probability of death resulting from infection by the fox variant of rabies may be low; however, if perceptions of risk is high, individuals receive a benefit from a perceived reduction in the probability that they will be infected with rabies. The recognition of all benefits when a government action is undertaken is vital to determining the total value, but cannot necessarily be included in the monetary calculations. Pet and livestock vaccinations, potential loss of human life and intangible benefits were outside the scope of this study and as a result, these potential benefits were excluded. The omission of these costs decreased the total estimated benefits, potentially making the BCRs more conservative.

\section{Acknowledgements}

The authors wish to thank the staff of the OMNR library for their assistance in finding pertinent documents for this study. We also thank the members of the Ontario Rabies Research Unit upon whose hard work this manuscript depends. We would also like to thank Drs Ray Sterner, Kathy Fagerstone and Rick Rosatte for their helpful critiques of this analysis.

Mention of companies or commercial products does not imply recommendation or endorsement by the U.S. Department of Agriculture over others not mentioned. USDA neither guarantees nor warrants the standard of any product mentioned. Product names are mentioned solely to report factually on available data and to provide specific information.

\section{References}

Bachmann, P., R. N. Bramwell, S. J. Fraser, D. A. Gilmore, D. H. Johnston, K. F. Lawson, C. D. MacInnes, F. O. Matejka, H. E. Miles, M. A. Pedde, and D. R. Voigt, 1990: Wild carnivoreacceptance of baits for delivery of liquid rabies vaccine. J. Wildl. Dis. 26, 486-501.

Boardman, A. E., D. H. Greenberg, A. R. Vining, and D. L. Weimer, 1996: Cost-Benefit Analysis: Concepts and Practice. Prentice Hall, Upper Saddle River, NJ.

Chang, H., M. Eidson, C. Noonan-Toly, C. V. Trimarchi, R. Rudd, and B. J. Wallace, 2002: Public health impact of re-emergence of rabies, New York. Emerg. Infect. Dis. 8, 909-913.

Enders, W., 1995: Applied Econometric Time Series. John Wiley \& Sons, Inc., New York, NY.

Foroutan, P., M. I. Meltzer, and K. A. Smith, 2002: Cost of distributing oral raccoon-variant rabies vaccine in Ohio: 1997-2000. J. Am. Vet. Med. Assoc. 220, 27-32.

Hauschildt, P., R. Tinline, and D. G. Ball, 2001: Out Foxing Rabies in Ontario. GPS World May, 12, 34-39.

Kemere, P., M. K. Liddel, P. Evangelou, D. Slate, and S. Osmek, 2002: Economic analysis of a large scale oral vaccination program to control raccoon rabies. In: L. Clark, J. Hone, J. A. Shivik, R. A. Watkins, K. C. Vercauteren, and J. K. Yoder (eds), Human Conflicts with Wildlife: Economic Considerations, pp. 109-115. U.S. Department of Agriculture, Animal and Plant Health Inspection Service, National Wildlife Research Center, Fort Collins, CO.

King, D. M., and M. Mazzotta, 2006: Ecosystem Valuation: Damage Cost Avoided, Replacement Cost and Substitute Cost Methods. Available at: http://www.ecosystemvaluation. org [cited 1 December 2006].

Kreindel, S. M., M. McGill, M. I. Meltzer, C. E. Rupprecht, and A. J. DeMaria, 1998: The cost of rabies postexposure prophylaxis: one state's experience. Public Health Rep. 113, 247-251.

Loomis, J. B., 1993: Integrated Public Lands Management: Principles and Applications to National Forests, Parks, Wildlife Refuges and BLM Lands. Columbia University Press, New York.

Loomis, J. B., and R. G. Walsh, 1997: Recreation Economic Decisions: Comparing Benefits and Costs, 2nd edn. Venture Publishing Inc., State College, Pennsylvania.

MacInnes, C. D., S. M. Smith, R. R. Tinline, N. R. Ayers, R. Bachmann, D. G. Ball, L. A. Clader, S. J. Crosgrey, C. Fielding, P. Hauschildt, J. M. Honig, D. H. Johnston, K. F. Lawson, C. P. Nunan, B. Pond, R. B. Stweart, and D. R. Voigt, 2001: Elimination of rabies from red foxes in eastern Ontario. J. Wildl. Dis. 37, 119-232.

Meltzer, M. I., 1996: Assessing the costs and benefits of an oral vaccine for raccoon rabies: a possible model. Emerg. Infect. Dis. 2, 343-349. 
Meltzer, M. I., and C. E. Rupprecht, 1998a: A review of the economics of the prevention and control of rabies, Part 1: Global impact and rabies in humans. Pharmacoeconomics 14, 366-383.

Meltzer, M. I., and C. E. Rupprecht, 1998b: A review of the economics of the prevention and control of rabies, Part 2: Rabies in dogs, livestock and wildlife. Pharmacoeconomics 14, 481-498.

Nas, T. F., 1996: Cost-Benefit Analysis: Theory and Application. Sage Publications Inc., California.

Nunan, C. P., R. R. Tinline, J. M. Honig, D. G. Ball, P. Hauschildt, and C. A. LeBer, 2002: Postexposure Treatment and Animal Rabies, Ontario, 1958-2000. Emerg. Infect. Dis. 8, 214-217.

Quantitative Micro Software, LLC, 1994: EViews 4. Quantitative Micro Software, LLC, Irvine, CA.

Rosatte, R. C., M. J. Power, D. Donovan, J. C. Davies, M. Allan, P. Bachmann, B. Stevenson, A. Wandeler, and F. Muldoon, 2007: Elimination of Arctic Variant Rabies in Red Foxes, Metropolitan Toronto. Emerg. Infect. Dis. Available at: http://www.cdc.gov/ncidod/EID/13/1/25.htm [Jan 2007].

Shwiff, S. A., R. T. Sterner, M. Jay-Russell, S. Parikh, A. Bellomy, and M. I. Meltzer, 2007: Direct and indirect costs of rabies exposure: a retrospective study in Southern California (1998-2002). J. Wildl. Dis., 43, 227-233.
Shwiff, S. A., K. N. Kirkpatrick, and R. T. Sterner, 2008: Economic evaluation of an oral rabies vaccination program for control of a domestic dog-coyote rabies epizootic: 19952006. J. Am. Vet. Med. Assoc. 233, 1736-1741.

Uhaa, I. J., V. M. Data, F. E. Sorhage, J. W. Beckley, D. E. Roscoe, and R. D. Gorsky, 1992: Benefits and costs of using an orally absorbed vaccine to control rabies in raccoons. J. Am. Vet. Med. Assoc. 201, 1873-1882.

Zerbe, R. O., and D. D. Dively, 1994: Benefit-cost analysis: In Theory and Practice. HarperCollins College Publishers, New York.

\section{Supporting Information}

Additional Supporting Information may be found in the online version of this article:

Figure S1. ANOvA results for PET and AT cases preand post-ORV.

Figure S2. ANOVA results for indemnity payments preand post-ORV.

Please note: Wiley-Blackwell are not responsible for the content or functionality of any supporting materials supplied by the authors. Any queries (other than missing material) should be directed to the corresponding author for the article. 